\begin{tabular}{lllll}
\hline Variables & Biological & Baseline & 6 months & 12 months \\
\hline VAS & Infliximab & $66.95 \pm 24.15$ & $40.81 \pm 20.87^{*}$ & $29.00 \pm 16.82^{* * *}$ \\
& Rituximab & $60.79 \pm 23.49$ & $35.32 \pm 20.85^{* *}$ & $34.82 \pm 26.78^{*}$ \\
VGP & Infliximab & $63.52 \pm 24.78$ & $39.43 \pm 21.23 \dagger$ & $36.74 \pm 19.91^{* * *}$ \\
& Rituximab & $60.79 \pm 19.45$ & $39.05 \pm 22.99 \ddagger$ & $36.65 \pm 25.76^{* *}$ \\
HAO & Infliximab & $1.996 \pm 0.764$ & $1.296 \pm 0.569 \dagger$ & $1.00 \pm 0.551^{* * *}$ \\
& Rituximab & $1.680 \pm 0.763$ & $1.184 \pm 0.906^{* * *}$ & $1.04 \pm 0.854^{* * *}$ \\
\hline${ }^{*} p=0.011$ & & & \\
${ }^{* *} p=0.018$ & & & \\
${ }^{* * *} p<0.0005$ & & & \\
$\dagger p=0.002$ & & & \\
$f^{\prime} p^{\prime}$ non-significant & & &
\end{tabular}

biological treatment, compared to $100 \%$ in rituximab's group. Results in table 1

Conclusions Infliximab and rituximab succeeded in improving the functional capacity of our patients, as well as gain a better perception of their clinical condition in the first 6 months of treatment. Infliximab got further reduction in VAS and VGP and before than rituximab. This may be because patients treated with rituximab had a more aggressive form, with previous failure to another biological in 100\%. Also note that the baseline $\mathrm{HAO}$ of patients with rituximab was lower than infliximab's group. It is probably because, despite the need for change in treatment for persistent activity, other patients had an improvement in functional capacity after the first biological treatment.

\title{
A208 IMPACT OF TWO BIOLOGICAL TREATMENTS IN THE FUNCTIONAL CAPACITY OF A COHORT OF PATIENTS WITH RHEUMATOID ARTHRITIS
}

Martínez-Pérez R, Rodríguez-Montero S, Muñoz A, León M, Gallo F, Velloso ML, Marenco JL Rheumatology Unit, Valme University Hospital, Seville, Spain

10.1136/ard.2010.149021.18

Introduction Rheumatoid arthritis is a chronic inflammatory disease that can lead to disability in most patients. There are several ways to estimate the functional capacity, currently the most widespread methods are specific questionnaires for rheumatic diseases as HAQ (Health Assessment Questionnaire). This questionnaire is based on the patient's own opinion about their disease and it's a standardised instrument with proven reliability and validity, among which include disabilities, especially in relation with physical function and pain. The authors' aim is to demonstrate that rituximab and infliximab improve functional capacity of our patients and to assess which treatment group gets the best response.

Material and methods Observational, descriptive and retrospective study. The authors analysed 42 patients with rheumatoid arthritis. Twenty-three patients received infliximab, versus 19 rituximab. The authors excluded those patients who had started treatment for less than 6 months. They used several variables: visual analogue scale (VAS), patient global assessment (VGP) and $\mathrm{HAQ}$, analysing before starting treatment, at 6 and 12 months.

Results Forty-two patients, 12 men (28.6\%) and 30 women $(71.4 \%)$. Only $4.8 \%$ of infliximab's group received previous 